\title{
On-line social interactions and executive functions
}

\author{
Oscar Ybarra ${ }^{1}$ and Piotr Winkielman ${ }^{2}$ \\ ${ }^{1}$ Adaptive Social Cognition Lab, Department of Psychology, University of Michigan, Ann Arbor, MI, USA \\ ${ }^{2}$ Department of Psychology, University of California at San Diego, La Jolla, CA, USA
}

\author{
Edited by: \\ Chris Frith, Wellcome Trust Centre for \\ Neuroimaging at University College \\ London, UK \\ Reviewed by: \\ Rebecca Elliott, University of \\ Manchester, UK \\ lan Apperly, University of \\ Birmingham, UK \\ *Correspondence: \\ Oscar Ybarra, Adaptive Social \\ Cognition Lab, Department of \\ Psychology, University of Michigan, \\ 530 Church Street, Ann Arbor, MI \\ 48109, USA. e-mail: \\ oybarra@umich.edu
}

A successful social interaction often requires on-line and active construction of an everchanging mental-model of another person's beliefs, expectations, emotions, and desires. It also requires the ability to maintain focus, problem-solve, and flexibly pursue goals in a distraction-rich environment, as well as the ability to take-turns and inhibit inappropriate behaviors. Many of these tasks rely on executive functions (EF) - working memory, attention/cognitive control, and inhibition. Executive functioning has long been viewed as relatively static. However, starting with recent reports of successful cognitive interventions, this view is changing and now EFs are seen as much more open to both short- and long-term "training," "warm-up," and "exhaustion" effects. Some of the most intriguing evidence suggests that engaging in social interaction enhances performance on standard EF tests. Interestingly, the latest research indicates these EF benefits are selectively conferred by certain on-line, dynamic social interactions, which require participants to mentally engage with another person and actively construct a model of their mind. We review this literature and highlight its connection with evolutionary and cultural theories emphasizing links between intelligence and sociality.

Keywords: socializing, executive function, on-line social cognition, mental fitness
Consider a simple act of tossing a ball toward a basketball hoop. To be successful, this act requires the ability to integrate and represent many bits of information, including the body's position, information about how the ball feels in ones hands, knowledge about the ball's kinematics, and visual cues indicating distance to the hoop, for example. Now consider trying to succeed at this task when other players are involved, running around on the court. Some of the same mental calculations have to be executed regarding ball tossing, but now the task is much more complex, as the other players in dynamic social context have to be taken into consideration. This necessitates that the perceiver track who is friend or foe, where the other players are, what goals their behavior suggests, and how to coordinate with them. The complex nature of calculating ball trajectories and physical causality is now amplified by the complexity of determining human intentions to help teammates and to try to outsmart competitors (Camerer, 2003). Further, to be effective, all of this has to be done in real time where speed and responsiveness matter, but in conjunction with the ability to keep plays and plans in mind and the ability to update the progress of the game.

In on-line social interaction - as it unfolds in real life and not just the basketball court - the involved parties run the risk of catching each other's gaze, smelling each other's breath, and even patting each other on the back after a good shot or as a sign of support. Being plugged into Facebook probably does not qualify as a mentally rich, on-line social interaction (even though it does occur "on-line"), nor does trying to conjure up an image of a person or a person's mind while in a brain scanner. Clearly, important progress has been made regarding the neural correlates of off-line social cognition, and there are some attempts to introduce elements of real social interaction in neuroimaging paradigms (Tomlin et al., 2006). However, a genuine, on-line social interaction is a dynamic and somewhat unstructured event, and many times the involved parties are moving targets with goals of their own, which implicates different cognitive processes for social understanding to occur.

Of course not all social interactions are the same, as they can differ in myriad ways. They can involve routinized daily encounters with acquaintances and simple greetings on the street. But they also can involve a diverse range of more intense social interactions, spanning the gamut from forming impressions on dates and performance in job interviews, to discussions of policies with colleagues, consultations of clothing choices with a sensitive spouse, bargaining with a sneaky salesperson, to performing a complex dance, playing a bridge game, or having a diplomatic negotiation. Often, to be effective in the latter, complex and often more consequential type of social interaction a perceiver is required to develop an on-line representation of a dynamic and changing mental-model of another person's beliefs, expectations, emotions, and desires. The perceiver also must be able to problem-solve, inhibit inappropriate behaviors, take-turns, and pursue goals in a distraction-rich environment.

Clearly, some mental processes in social interaction are automatic and largely environment-driven, and they may not even rise to the level of "implicit mentalizing" (Leudar and Costall, 2008). Other mental processes might be inferential but still be spontaneous and efficient (e.g., Winter and Uleman, 1984; Trope, 1986). Thus, people can achieve some level of mentalizing and social understanding through processes that do not draw on executive functions (EFs; e.g., Flavell et al., 1981; Onishi and Baillargeon, 2005; Moll and Tomasello, 2006; Qureshi et al., 2010; Samson et al., 2010). However, it is also clear that many times during real 
social interaction some social cognition relies on EF. For example, the link between social reasoning and EF has long been emphasized in the theory-of-mind literature (Hughes and Ensor, 2007; Apperly et al., 2009). With ineffective executive functioning people should be less able to track and update the meaning being created in a conversation, be less able to consider another person's perspective, or be less able to negotiate, which bodes poorly for social coordination and acceptance by others. Accordingly, investigating the effects that social factors have on EFs appears scientifically fruitful and important to understanding the nature of on-line social cognition. In this short review, we discuss how EFs are shaped by social interaction and highlight discoveries suggesting that on-line and off-line social cognition differ in the nature of EF involvement.

\section{EXECUTIVE FUNCTIONS IN PSYCHOLOGY AND THEIR MALLEABILITY}

Different ways exist to conceptualize executive functioning. For research that has applied latent statistical models, the focus is on classification and documenting both the diversity and unity of EFs. Although related, EFs can be classified into three categories, including (i) working memory and updating, (ii) executive attention or cognitive control, and (iii) inhibition (e.g., Miyake et al., 2000; Friedman et al., 2006; Miyake and Friedman, 2012). But the three aspects also form an integrated mechanism for processing information. This broader mechanism underlies the ability to manipulate and maintain tasks, plans, and goals (i.e., their mental representations) in an active state while monitoring performance and inhibiting distracting stimuli, whether from the environment or internally (Kane and Engle, 2002).

Executive functioning is a central topic in many areas of psychology (Posner and Rothbart, 2007). Various theoretical frameworks emphasize that while some cognitive processes can run efficiently on limited cognitive resources, many others engage executive functioning. Within social psychology, EFs are important for a wide array of sub-fields that inform the nature of social behavior, including persuasion, attitudes and prejudice, social perception, self-control, and emotion regulation, for example (e.g., Smith and DeCoster, 2000; von Hippel, 2007). In all these areas of social functioning, automatic processes are thought to help create a "first-pass," working model of the event (e.g., perceiver readily infers a speaker seems competent due to style of dress). Assuming the perceiver is motivated and has the requisite cognitive resources (EFs), they then can integrate more information about the event to enrich the working model and arrive at a deeper social understanding (for reviews, see Chaiken and Trope, 1999; Smith and DeCoster, 2000).

One central question about EFs in day-to-day life is their malleability. Except for changes across the lifespan (e.g., von Hippel, 2007), people's executive functioning has long been viewed as relatively static - perhaps because of robust individual differences in EFs. However, starting with recent reports of successful cognitive interventions, this view has begun to change and now EFs are seen as much more open to both short- and long-term "training," "warm-up," and "exhaustion" effects. Research has shown, for example, that working memory training not only leads to improvements on distinct measures of executive functioning but also to transfer effects resulting in improvement on measures of fluid intelligence (e.g., Jaeggi et al., 2008, 2011). In young children, cognitive training has been shown to improve subsequent attention control (e.g., Thorell et al., 2008). Other findings indicate EFs benefit from meditation training (e.g., Tang and Posner, 2009).

However, some of the most intriguing evidence comes from research showing that social engagement enhances performance on standard EF tests. This is important since the majority of people's life takes place in the social world - interacting on-line with other humans.

\section{SOCIAL INTERACTION AND EXECUTIVE FUNCTIONING ON-LINE SOCIAL INTERACTION AND EXECUTIVE FUNCTIONING BOOSTS}

It has long been argued that communicating with others, taking others' perspectives, and following social rules sets the stage for the development and maintenance of EFs, thus helping structure general mental functioning (e.g., Vygotsky, 1978; Buttelmann et al., 2009). As previously mentioned, the developmental literature has long linked EFs to performance on some aspects of ToM (Hughes and Ensor, 2007). Selection pressures related to the complex, dynamic and mixed-motive nature of social life have also been posited to partly underlie the evolution of primate intelligence (e.g., Jolly, 1966; Humphrey, 1976; Dunbar and Shultz, 2007). There also are intriguing suggestions regarding the overlap of the neural underpinnings of EF and social reasoning processes (von Hippel, 2007; Adolphs, 2009). And there are now several reports of positive correlations of some brain structures with social network size. For example, amygdala size correlates with the size and complexity of real social networks (Bickart et al., 2011), whereas gray matter correlates with the number of Facebook friends (Kanai et al., 2011). More impressively, it appears that, at least in macaques, social network size causally influences brain structure and function (Sallet et al., 2011).

With humans, much cross-sectional and longitudinal research has found positive relationships between social participation/engagement and executive functioning and related mental health outcomes (e.g., Fratiglioni et al., 2004). Some findings with distinct populations also indirectly support the notion that EFs benefit from social processes. Thus, for example, a Vygotskian based curriculum (Tools of the mind) - which requires much social interaction and taking others' perspective - boosted not only preschoolers' social skills but also their executive functioning (e.g., Diamond et al., 2007). Although most of the available work examining the effects of social engagement relies on correlational designs, a few studies are beginning to show positive causal effects of social processes on executive functioning, and the most direct evidence comes from social psychological research investigating the effect of on-line social interaction on executive functioning.

In one experiment, we had participants interact by having a discussion of a social topic (Ybarra et al., 2008). Participants were given 10 min total, with a few minutes to prepare for the discussion. Following the interaction the participants evaluated the activity and then completed tests of cognitive functioning, in 
particular a test of working memory which is a critical component of executive functioning. We also tested participants assigned to either an intellectual activities condition or a control condition that involved watching a 10 -min video. The findings indicated the social interaction group outperformed the controls. Further, social interaction benefited EF performance similarly to the intellectual activities.

Another aspect of this "mental exercising through simple socializing" research that should be highlighted is that participants assigned to the video condition were presented with social content involving several human characters that were engaged in social interaction (Ybarra et al., 2008). In a sense, the video content represents a rich stimulus compared to many of the stimuli used to study social cognitive processes from a neuroscientific perspective. Still, the video condition did not result in any boosts to EFs; it was the real, on-line social interaction that resulted in EF boosts, which were equivalent to those resulting from engaging in difficult intellectual activities. Thus, benefits to EFs are selectively seen in on-line social cognition, where participants dynamically construct a model of another person, and less in off-line social cognition where participants deal with static or impoverished and less engaging representations of others.

Regarding the above research, the argument could be made that the discussion that comprised the social interaction was atypical in some way, in that participants had to take positions, make arguments, and discuss their point of view. But as recent theorizing on the evolution of reasoning suggests, this aspect of social interaction - evaluating arguments and proffering others - may have been an important pressure on the evolution of our distinctive human cognition (Mercier and Sperber, 2011). Further, as we will discuss later, recent research indicates EF boosts also can result from basic get-to-know-you interactions if structured in a particular, mind-engaging way (Ybarra et al., 2011). So the positive effects on EFs can occur from other types of on-line social interactions.

\section{ON-LINE SOCIAL INTERACTION AND EXECUTIVE FUNCTIONING REDUCTIONS}

Our own research suggests that social interaction can boost EFs. However, evidence also exists for the detrimental effects of some social interactions on EFs. Most of these findings come from research on intergroup social interactions (e.g., Richeson and Trawalter, 2005). In one study, for example, participants who underwent an interracial interview compared to a same race interview subsequently exhibited more interference on a Stroop task, a measure of EF. Further, this effect was greater the stronger participants' associations between concepts denoting African-Americans and negative personality characteristics, as measured with the IAT test. These negative effects on EFs were undone by lessening participants' concerns about appearing prejudiced.

Another form of intergroup context involves interactions between men and women. Studies found that after interacting with an attractive female, men showed worse performance on a subsequent $\mathrm{EF}$ task, and the decline was related to the degree men tried to manage their impression in the interaction (Karremans et al., 2009).
Research also has shown that challenging or "high maintenance" interactions can result in reduction of cognitive functioning (Finkel et al., 2006). These investigators had participants coordinate on a task with a confederate, who in some cases made scripted errors (high maintenance) and in some cases did not (low maintenance). Participants in the high maintenance condition performed worse on various subsequent tests, although in this research the tests were indirectly tied to EFs.

\section{SOLVING THE SOCIAL INTERACTION-EXECUTIVE FUNCTION PUZZLE}

The findings that social interactions influence executive functioning are fascinating. They might also be surprising given that many times social processes are considered "soft" and distinct from intellectual and reasoning processes. However, the findings are also puzzling. Why do some interactions lead to EF impairments but other interactions to benefits?

One solution emerges when we consider the social cognitive mechanisms underlying social interaction. Note that most, if not all, studies showing EF reductions invoked self-presentation concerns (e.g., about appearing non-prejudiced, unintelligent, etc.). This concern has several consequences that persist beyond the initial interaction. First, it constitutes a working memory load ("what was the interaction about?" "how did I do?," etc.). Second, it triggers effortful attempts to self-regulate, which, if extensive, could deplete cognitive resources (Muraven and Baumeister, 2000). At a broader level this reasoning also applies to some of the findings dealing with performance decrements under conditions of stereotype threat, for example.

In our opinion, however, one key difference between studies showing reductions and boosts in EFs has to do with the nature of the interaction. In particular, it is critical whether participants mentally engage with others and attempt to build a rich model of their minds, that they toggle between self and other perspectives, and that they communicate and create meaning during the social interaction versus disengage from the interaction. We argue that this is often, though not always (see below), determined by whether the interaction is cooperative or competitive. Clearly, both interaction types can invoke mentalizing. However, the default in a cooperative setting is often to engage with the other person, build a model of their mind, figure out whether or not they are trustworthy, and convey to them that they can trust us. In fact, under these trust-building conditions neuroimaging work has reported some of the most robust effects of mentalizing on activity in the medial prefrontal cortex (for reviews, see Frith and Singer, 2008). Further, children's ability to mentalize (i.e., perform ToM tasks) has been shown to be positively correlated to the likelihood of cooperating, for example, in prisoner's dilemma games and also to making fair offers in the ultimatum game (Sally and Hill, 2006; also see Buttelmann et al., 2009).

In contrast, the default under competitive goals, as realized in the above research on intergroup interactions, is often to become self-protective and withdraw from engaging the other person. This may occur because the interaction is ambiguous and not well structured, which inclines people to back away from the situation as a general way of deterring interpersonal costs (Ybarra et al., 2010). 
This may also occur because people have a tendency to "dehumanize" outgroups and thus attribute less mind to their competitors (Harris and Fiske, 2006). Finally, it is possible that competition (but also other high-stake situations) may sometimes usurp the cognitive resources necessary for careful and effortful mentalizing. So, people focus on themselves and their own interests rather than the other person, and they do not engage in attempts to take perspective and create a rich model of the other and the event.

A key aspect then of whether or not social interaction creates subsequent EF boosts rests on people engaging each other. We propose that doing so invokes processes that exercise underlying EFs, such as working memory and executive attention. Thus, when people engage with others in social interaction, versus withdraw into themselves, they can exercise or "warm-up" these core cognitive processes, whose influence is then transferred (far) to executive functioning tasks (Ybarra et al., 2008).

If such social cognitive processes underlie the cognitive boosts, disrupting them should eliminate the cognitive benefits. Consistent with this idea, our recent experiments found that interaction goals (competition) that disengage participants from perspective taking and mentalizing eliminate the cognitive benefits that can result from social interaction (Ybarra et al., 2011, Study 1). Importantly, follow-up work has shown that getting people to engage others during interaction, even when the interaction is competitive, helps counter the loss in cognitive benefits (Ybarra et al., 2011, Study 3). This is consistent with other research in social cognition suggesting that skepticism, suspiciousness, and other "competitive" approaches can sometimes improve mental performance (Schul et al., 2004, 2008). These findings provide evidence that engaging the other during interaction along with concomitant social cognitive processing (perspective taking, mind-reading) may partly underlie the boosts to executive functioning following social interaction.

The above findings also help inform, at least in some small measure, the assumption that competition in social contexts played an important role in the evolution of primate cognition and the more intense varieties of social cognition and mentalizing (e.g., Byrne and Whiten, 1988; Whiten and Byrne, 1997). Dealing with competitors can of course implicate the understanding of others' behavioral tendencies and psychological states (e.g., Tomasello et al., 2003; Decety et al., 2004), but as we have shown in our experiments, people who expect to compete during social interaction, if not given an explicit goal to read the other person and form a model of what they are like, will disengage and behave evasively (Ybarra et al., 2010) and not receive cognitive benefits from the interaction (Ybarra et al., 2011). These findings suggest that people when competing have diverse options they can undertake, such as to try to hide or foil prediction. Only when no, low-risk option is available will they engage or confront the opponent. This, however, does not mean some level of social understanding is not sought or created under competitive circumstances, but it may be that the working model of the other is of a generic, stereotypic nature that relies less on EFs, similar to the social perception differences found when people judge members of outgroups versus ingroups (Neuberg and Fiske, 1987; Brewer, 1988). When interdependence is called for - meaning you have to interact on-line with a person and that your behavior is to some degree yoked to theirs - the situation should instigate more intense social cognition and mentalizing to build a richer model of the other party.

The discussion of competition helps highlight the role we assign to mentalizing and understanding others' psychological states during social interaction. We propose that mental engagement with others leads to cognitive benefits from social interaction especially when the involved parties are taking perspective and dynamically building a model of what the other person is like. As we noted in the introduction, some social inferential processes can occur quite efficiently with little reliance on EFs (e.g., Winter and Uleman, 1984; Trope, 1986). A similar theme comes up in research on theory of mind, with certain processes (e.g., the calculation of what another sees) thought to be carried out efficiently and automatically (e.g., Moll and Tomasello, 2006; Onishi and Baillargeon, 2005; Qureshi et al., 2010). Related ideas on the role of efficient social understanding also have been discussed from the point of view of embodied and situated social cognition (Leudar et al., 2004; Barrett and Henzi, 2005; Iacoboni et al., 2005). However, some ToM and mentalizing processes such as the selection of information for further processing, though, are thought to require limited cognitive resources or EF (e.g., Leslie et al., 2005; Bull et al., 2008; Qureshi et al., 2010), and engagement with others in social interaction is considered the real domain in which minds are known (Reddy and Morris, 2004).

Thus, there are important elements of building a model of what another person is like, what they are thinking, and what they might do next that rely on EFs. Our proposal is that during real social interaction both low-level and high-level mentalizing and behavior prediction processes interact and inform each other. The automatic processes serve as input that feed into richer representations that are shaped and updated by processes requiring limited cognitive resources in real time. As noted with competition, it is not that people who are dealing with antagonistic parties fail to attempt to understand their foes - some basic and generic calculations take place. But it is during social interaction when the parties are actively engaged with each other that richer representations of the other and of the interaction are created and dynamically updated, which entails the participation of EFs. It is such interactions that we believe result in cognitive benefits.

In addition to the issues discussed above, further work is needed to address the following questions:

- What specific types of social interactions benefit EF and what are the underlying processes that underlie theses boosts?

- Given both the unity and diversity of EFs, does social interaction affect some EF elements more than others, or does this also depend on the type of interaction?

- How long do cognitive boosts last and what is there time course, and does this depend on the task to which the cognitive processes are applied?

- Are the neural correlates underlying on-line social interaction, in particular those underlying EFs, similar or different from the correlates unearthed for off-line social interaction? 
- How do short-term training effects of social interaction translate into long-term cognitive reserve, which may be captured in the cross-sectional and longitudinal studies on social engagement and cognitive functioning?

- And, what are the longer-term consequences of repeated interactions that result in EF reductions? If people do not avoid others different from the self, can they learn to cope with such challenging interactions? If so, could this subsequently mitigate EF reductions and possibly even create boosts?

\section{PRACTICAL IMPLICATIONS}

In addition to theoretical implications regarding the difference between real, on-line social cognition versus off-line social cognition, the processes discussed here have several practical implications. The major one is that certain social interactions can be an effective way of "keeping mentally fit." People are becoming ever more interested in improving their mental fitness. SharpBrains, a company that tracks the mental fitness industry, estimated that worldwide revenue associated with cognitive training programs (e.g., computer software) surged to $\$ 850$ million in 2008 , up from $\$ 250$ million in 2005 . This is a positive development as people actively try to improve their cognitive functioning.

Unfortunately, many of these training programs are not only expensive, but few have been scientifically evaluated (Jaeggi et al., 2011). More germane to this proposal, what is important to emphasize is that what also matters is engagement and taking an active and not a passive role to the technology or the social interaction. As reviewed earlier, some forms of social interaction result in no boosts, whereas those in which the parties were engaged and actively tried to form a working model of the other yielded cognitive benefits. However, we would add that given that social connections are at the core of primate life (Jolly, 1966), are central to the human survival strategy (Barash, 1986; Dunbar, 1992, 1998; Baumeister, 2005), and yield various benefits to health and well-being (e.g., House et al., 1988; Ybarra et al., 2008), engaged socializing with others in cooperative interaction may not only

\section{REFERENCES}

Adolphs, R. (2009). The social brain: neural basis of social knowledge. Annu. Rev. Psychol. 60, 693-716.

Apperly, I. A., Samson, D., and Humphreys, G. W. (2009). Studies of adults can inform accounts of theory of mind development. Dev. Psychol. 45, 190-201.

Barash, D. P. (1986). Sociobiology and Behavior. New York: Elsevier.

Barrett, L., and Henzi, S. P. (2005). The social nature of primate cognition. Proc. R. Soc. Lond. B Biol. Sci. 272, 1865-1875.

Baumeister, R. F. (2005). The Cultural Animal: Human Nature, Meaning, and Social Life. New York: Oxford University Press.

Bickart, K. C., Wright, C. I., Dautoff, R. J., Dickerson, B. C., and Barrett L. F. (2011). Amygdala volume and social network size in humans. Nat. Neurosci. 14, 163-164.
Brewer, M. B. (1988). "A dual process model of impression formation," in Advances in Social Cognition, Vol. 1, eds T. K. Srull and R. S. Wyer (Hillsdale, NJ: Lawrence Erlbaum Associates), 1-36.

Bull, R., Phillips, L. H., and Conway, C. A. (2008). The role of control functions in mentalizing: dual-task studies of theory of mind and executive function. Cognition 107, 663-672.

Buttelmann, D., Carpenter, M., and Tomasello, M. (2009). Eighteenmonth-old infants show false belief understanding in an active helping paradigm. Cognition 112, 337-342.

Byrne, R. W., and Whiten, A. (1988). Machiavellian Intelligence. Oxford: Oxford University Press.

Camerer, C. F. (2003). Behavioral Game Theory: Experiments in Strategic Interaction. Princeton, NJ: Princeton University Press.

strengthen people's brains and minds but possibly their social relations as well, allowing them to reap the various benefits that flow from such bonds.

\section{CONCLUSION}

In short, our review highlights the essential role of studying on-line social interactions for understanding the operation of fundamental cognitive processes. The reviewed findings also have practical implications for keeping mentally fit. Although we focused on how executive functioning can change due to task context, especially the on-line social context, it is also important to appreciate the role of people's beliefs and strategies in social navigation.

Most of us probably know people who seem quite intelligent but still do many dumb things in "real life." A good analogy for this is a high-performance computer running bad software. The $\mathrm{CPU}$ is a work of exquisite engineering, but if you try to use such a computer, task performance will be suboptimal and frustrating. The point here is simple: "raw" executive functioning matters for many social tasks, but so does the content of people's beliefs and strategies - their rationality and match to the environment (both in terms of controlled and automatic mental processes). Social life affects executive functioning. But social life, especially who people interact and associate with, also plays a central role in the beliefs and values that end up populating people's minds.

\section{ACKNOWLEDGMENTS}

Correspondence can be addressed to either author. Piotr Winkielman is on the faculty in the Psychology Department at the University of California, San Diego. We would like to thank Bill Gehring and David Liu for their comments on an earlier version of this draft, and the reviewers for their generous feedback. The research was supported by the Key Discipline Fund of the National 211 Project, China. Oscar Ybarra's primary appointment is at the University of Michigan; he is a visiting professor in the Summer at Southwest University.

Chaiken, S., and Trope, Y. (1999). Dual Process Theories in Social Psychology. New York: Guilford Press.

Decety, J., Jackson, P. L., Sommerville, J. A., Chaminade, T., and Meltzoff, A. N. (2004). The neural bases of cooperation and competition: an fMRI investigation. Neuroimage 23, 744-751.

Diamond, A., Barnett, W. S., Thomas, J., and Munro, S. (2007). Preschool program improves cognitive control. Science 318, 1387-1388.

Dunbar, R. I. M. (1992). Neocortex size as a constraint on group size in primates. J. Hum. Evol. 20, 469-493.

Dunbar, R. I. M. (1998). The social brain hypothesis. Evol. Anthropol. 6, 178-190.

Dunbar, R. I. M., and Shultz, S. (2007). Evolution in the social brain. Science 317, 1344-1347.

Finkel, E. J., Campbell, W. K., Brunell, A. B., Dalton, A. N., Chartrand,
T. L., and Scarbeck, S. J. (2006). High-maintenance interaction: inefficient social coordination impairs self-regulation. J. Pers. Soc. Psychol. 91, 456-475.

Flavell, J. H., Everett, B. A., Croft, K., and Flavell, E. R. (1981). Young children's knowledge about visual perception: further evidence for the level 1-level 2 distinction. Dev. Psychol. 17, 99-103.

Fratiglioni, L., Paillard-Borg, S., and Winblad, B. (2004). An active and socially integrated lifestyle in late life might protect against dementia. Lancet Neurol. 3, 343-353.

Friedman, N. P., Miyake, A., Corley, R. P., Young, S. E., DeFries, J. C., and Hewitt, J. K. (2006). Not all executive functions are related to intelligence. Psychol. Sci. 17, 172-179.

Frith, C. D., and Singer, T. (2008). The role of social cognition in decision making. Philos. Trans. R. Soc. Lond. B Biol. Sci. 363, 3875-3886. 
Harris, L. T., and Fiske, S. T. (2006). Dehumanizing the lowest of the low - neuroimaging responses to extreme out-groups. Psychol. Sci. 17, 847-853.

House, J. S., Landis, K. R., and Umberson, D. (1988). Social relationships and health. Science 241, 540-545.

Hughes, C., and Ensor, R. (2007). Executive function and theory of mind: predictive relations from ages 2 to 4 . Dev. Psychol. 43, 1447-1459.

Humphrey, N. K. (1976). "The social function of intellect," in Growing Points in Ethology, eds P. P. G. Bateson and R. A. Hinde (Cambridge: Cambridge University Press), 303-317.

Iacoboni, M., Molnar-Szakacs, Gallese, V., Buccino, G., Mazziotta J. C., and Rizzolatti, G. (2005). Grasping the intentions of others with one's own mirror neuron system. PLoS Biol. 3, 529-535. doi: 10.1371/journal.pbio. 0030079

Jaeggi, S. M., Buschkuehl, M., Jonides, J., and Perrig, W. J. (2008). Improving fluid intelligence with training on working memory. Proc. Natl. Acad. Sci. U.S.A. 105, 6791-6792.

Jaeggi, S. M., Buschkuehl, M., Jonides, J., and Shah, P. (2011). Short- and long-term benefits of cognitive training. Proc. Natl. Acad. Sci. U.S.A. 108, 10081-10086.

Jolly, A. (1966). Lemur social behavior and primate intelligence. Science 153 , 501-506.

Kanai, R., Bahrami, B., Roylance, R., and Rees, G. (2011). Online social network size is reflected in human brain structure. Proc. R. Soc. Lond. B Biol. Sci. 279, 1327-1334.

Kane, M. J., and Engle, R. W. (2002). The role of prefrontal cortex in working-memory capacity, executive attention, and general fluid intelligence: an individual-differences perspective. Psychon. Bull. Rev. 9, 637-671.

Karremans, J. C., Verwijmeren, T., Pronk, T. M., and Reitsma, M. (2009). Interacting with women can impair men's executive functioning. J. Exp. Soc. Psychol. 45, 1041-1044.

Leslie, A. M., German, T. P., and Polizzi, P. (2005). Belief-desire reasoning as a process of selection. Cogn. Psychol. $50,45-85$.
Leudar, I., and Costall, A. (2008). Against Theory of Mind. Basingstoke: Palgrave/Macmillan, 39-55.

Leudar, I., Costall, A., and Francis, D. (2004). Theory of mind: a critical assessment. Theory Psychol. 14, 571-578.

Mercier, H., and Sperber, D. (2011). Why do humans reason? Arguments for an argumentative theory. Behav. Brain Sci. 34, 57-111.

Miyake, A., and Friedman, N. P. (2012). The nature and organization of individual differences in executive functions: four general conclusions. Curr. Dir. Psychol. Sci. 21, 8-14.

Miyake, A., Friedman, N. P., Emerson, M. J., Witski, A. H., Howerter, A., and Wager, T. (2000). The unity and diversity of executive functions and their contributions to complex "frontal lobe" tasks: a latent variable analysis. Cogn. Psychol. 41, 49-100.

Moll, G., and Tomasello, M. (2006). Level 1 perspective-taking at 24 months of age. Br. J. Dev. Psychol. 24, 603-613.

Muraven, M., and Baumeister, R. F. (2000). Self-regulation and depletion of limited resources. Does selfcontrol resemble a muscle? Psychol. Bull. 126, 247-259.

Neuberg, S. L., and Fiske, S. T. (1987). Motivational influences on impression formation: outcome dependency, accuracy-driven attention, and individuating processes. J. Pers. Soc. Psychol. 53, 431-444.

Onishi, K. H., and Baillargeon, R. (2005). Do 15-month-old infants understand false beliefs? Science 308 , 255-258.

Posner, M. I., and Rothbart, M. K. (2007). Research on attention networks as a model for the integration of psychological science. Annu. Rev. Psychol. 58, 1-23.

Qureshi, A., Apperly, I. A., and Samson, D. (2010). Executive function is necessary for perspective-selection, not level-1 visual perspective-calculation: evidence from a dual-task study of adults. Cognition 117, 230-236.

Reddy, V., and Morris, P. (2004). Participants don't need theories: knowing minds in engagement. Theory Psychol. 14, 647-665.

Richeson, J. A., and Trawalter, S. (2005). Why do interracial interactions impair executive function? A resource depletion account. J. Pers. Soc. Psychol. 88, 934-947.

Sallet, J., Mars, R. B., Noonan, M. P., Andersson, J. L., O'Reilly, J. X., Jbabdi, S., Croxson, P. L., Jenkinson, M., Miller, K. L., and Rushworth, M. F. S. (2011). Social network size affects neural circuits in macaques. Science $334,697-700$.

Sally, D., and Hill, E. (2006). The development of interpersonal strategy: autism, theory-of-mind, cooperation and fairness. J. Econ. Psychol. 27, 73-97.

Samson, D., Apperly, I. A., Braithwaite, J. J., Andrews, B. J., and Bodley Scott, S. (2010). Seeing it their way: what other people see is calculated by lowlevel and early acting processes. $J$. Exp. Psychol. Hum. Percept. Perform. 36, 1255-1266.

Schul, Y., Mayo, R., and Burnstein, E. (2004). Encoding under trust and distrust: the spontaneous activation of incongruent cognitions. J. Pers. Soc. Psychol. 86, 668-679.

Schul, Y., Mayo, R., and Burnstein, E. (2008). The value of distrust. J. Exp. Soc. Psychol. 44, 1293-1302.

Smith, E. R., and DeCoster, J. (2000). Dual process models in social and cognitive psychology: conceptual integration and links to underlying memory systems. Pers. Soc. Psychol. Rev. 4, 108-131.

Tang, Y. Y., and Posner, M. I. (2009). Attention training and attention state training. Trends Cogn. Sci. 13, 222-227.

Thorell, L. B., Lindqvist, S., Bergman, S. Bohlin, G., and Klingberg, T. (2008). Training and transfer effects of executive functions in preschool children. Dev. Sci. 11, 969-976.

Tomasello, M., Call, J., and Hare, B. (2003). Chimpanzees understand psychological states - the question is which ones and to what extent. Trends Cogn. Sci. 7, 153-156.

Tomlin, D., Kayali, M. A., KingCasas, B., Anen, C., Camerer, C. F., Quartz, S. R., and Montague, P. R. (2006). Agent-specific responses in the cingulate cortex during economic exchanges. Science 312, 1047-1050.

Trope, Y. (1986). Identification and inferential processes in dispositional attribution. Psychol. Rev. 93, 239-257. von Hippel, W. (2007). Aging, executive functioning, and social control. Curr. Dir. Psychol. Sci. 16, 240-244.

Vygotsky, L. (1978). Mind in Society. Cambridge, MA: Harvard University Press.

Whiten, A., and Byrne, R. W. (1997). Machiavellian Intelligence II: Extensions and Evaluations. Cambridge: Cambridge University Press.

Winter, L., and Uleman, J. S. (1984). When are social judgments made? Evidence for the spontaneousness of trait inferences. J. Pers. Soc. Psychol. $47,237-252$.

Ybarra, O., Burnstein, E., Winkielman, P., Keller, M. C., Manis, M., Chan, E., and Rodriguez, J. (2008). Mental exercising through simple socializing: social interaction promotes general cognitive functioning. Pers. Soc. Psychol. Bull. 34, 248-259.

Ybarra, O., Keller, M. C., Chan, E., Garcia, S. M., Sanchez-Burks, J., Rios Morrison, K., and Baron, A. S. (2010). Being unpredictable: friend or foe matters. Soc. Psychol. Pers. Sci. 1, 259-267.

Ybarra, O., Winkielman, P., Yeh, I., Burnstein, E., and Kavanagh, L. (2011). Friends (and sometimes enemies) with cognitive benefits: what types of social interactions boost cognitive functioning? Soc. Psychol. Pers. Sci. 2, 253-261.

Conflict of Interest Statement: The authors declare that the research was conducted in the absence of any commercial or financial relationships that could be construed as a potential conflict of interest.

Received: 29 December 2011; accepted: 17 March 2012; published online: 09 April 2012.

Citation: Ybarra $O$ and Winkielman $P$ (2012) On-line social interactions and executive functions. Front. Hum. Neurosci. 6:75. doi: 10.3389/fnhum.2012. 00075

Copyright (๑) 2012 Ybarra and Winkielman. This is an open-access article distributed under the terms of the Creative Commons Attribution Non Commercial License, which permits non-commercial use, distribution, and reproduction in other forums, provided the original authors and source are credited. 